\title{
Aging and Fall: Vision Related Signs on Head Computed Tomography
}

\author{
(D) Sunny Chi Lik Au, (1) Simon Tak Chuen Ko \\ Tung Wah Eastern Hospital, Clinic of Ophthalmology, Hong Kong, China
}

\section{To the editor,}

On a normal morning with passing clouds, a 69-year-old man fell on dry level ground during his regular morning walk after breakfast over the usual trail. He enjoyed good past health, without smoking and drinking, but history of bilateral consecutive retinal detachment (RD) surgery 2 years ago. He had high myopia of-10 Diopters before the eye operations, and was on nocte prostaglandin analogue, Latanoprost, for intraocular pressure (IOP) control. Latest best corrected visual acuity was Snellen 0.3 and 0.2 with IOP 13 and $11 \mathrm{mmHg}$ for right and left eye respectively. His post-operative refractions were -2.5 Diopters over both eyes with glasses for distance. There was no dizziness, nor chest discomfort. Medical workup in the hospital revealed stable 24-hour blood pressure without postural hypotension, and normal blood glucose level with fasting and HbA1c. Endocrine blood tests were all normal. Detailed examinations by physicians did not reveal any cerebral or cardiovascular cause for his fall episode, whereas gait, balancing, coordination, muscle strength assessments were all acceptable. Computed tomography (CT) of the brain was normal, except bilateral regular hyperdensities over the orbits, suggestive of bilateral buckles over each globe, and trochlear calcifications (Figure 1). Visual cause for his fall was concluded.

Elderly fall is common in our community, and visual cause is not rare (1). CT of the head is commonly performed for these patients, and clues for visual impairment may be seen (2). Although in elderly, RD and glaucoma affects daily living activities more from compromised peripheral visual field. Concerning our case, radiological signs on head $\mathrm{CT}$ for $\mathrm{RD}$, glaucoma and trochlear calcifications are discussed.
With high prevalence of myopia and less awareness in the past, $\mathrm{RD}$ is more common in Asian elderly. Before the era of vitrectomy, RD repair surgery requires explant to oppose the detached retina. This can be segmental buckle alone or in the form of encircling band. Commonly made of silicone with its inert and safety profile, these buckling materials appear as hyperdensity on CT. As retinal breaks are usually anteriorly located, and over superior quadrant, location of buckles follows. Bilateral RD is not common, and vitreous abnormalities other than high myopia should be considered.

Glaucoma is common in elderly, no matter from aging or cataract, inflammatory or iatrogenic causes. Being one of the top causes of blindness worldwide, glaucoma is mainly managed by IOP control. Treatment is evolving from traditional trabeculectomy to Glaucoma Drainage Devices. These devices appear as different shapes of hyperdensity on $\mathrm{CT}$, depending

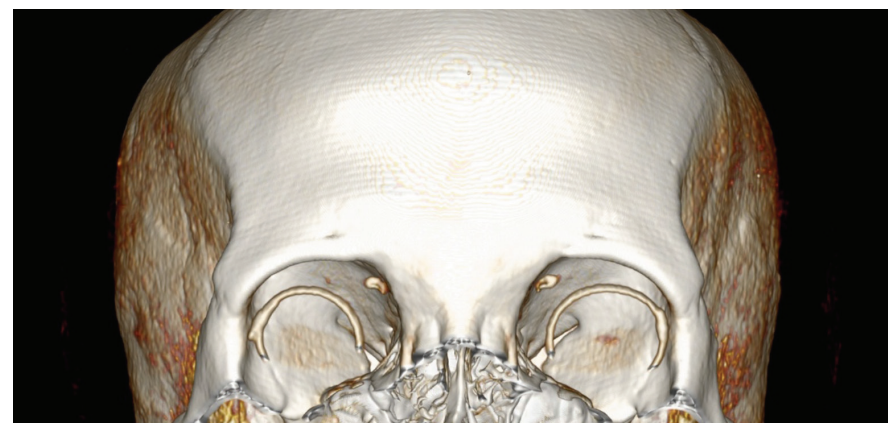

Figure 1. Vision related signs on head computed tomography

Signs over different planes were better demonstrated with 3D reconstruction of computed tomography of the superior orbit. Bilateral trochlear calcifications were seen over superomedial orbit, whereas bilateral encircling bands with sleeves over superotemporal quadrant outlines the globe position

Address for Correspondence: Sunny Chi Lik Au, Tung Wah Eastern Hospital, Clinic of Ophthalmology, Hong Kong, China E-mail: kilihcua@gmail.com ORCID: orcid.org/0000-0002-5849-3317

Received: Sep 25, 2019 Accepted: Nov 01, 2019

Cite this article as: Au SCL, Ko STC. Aging and Fall: Vision Related Signs on Head Computed Tomography. Eur J Geriatr Gerontol 2019;1(3):112-113

๑Copyright 2019 by the Academic Geriatrics Society / European Journal of Geriatrics and Gerontology published by Galenos Publishing House. 
on their composition materials such as the Ophthalmological Signet Ring sign (3).

Trochlear calcification, having $13 \%$ of prevalence in the population, appears as hyperdensity in the superomedial orbit; however it is not specific to age (4). Having similar proportion of unilateral and bilateral distribution, trochlear calcification

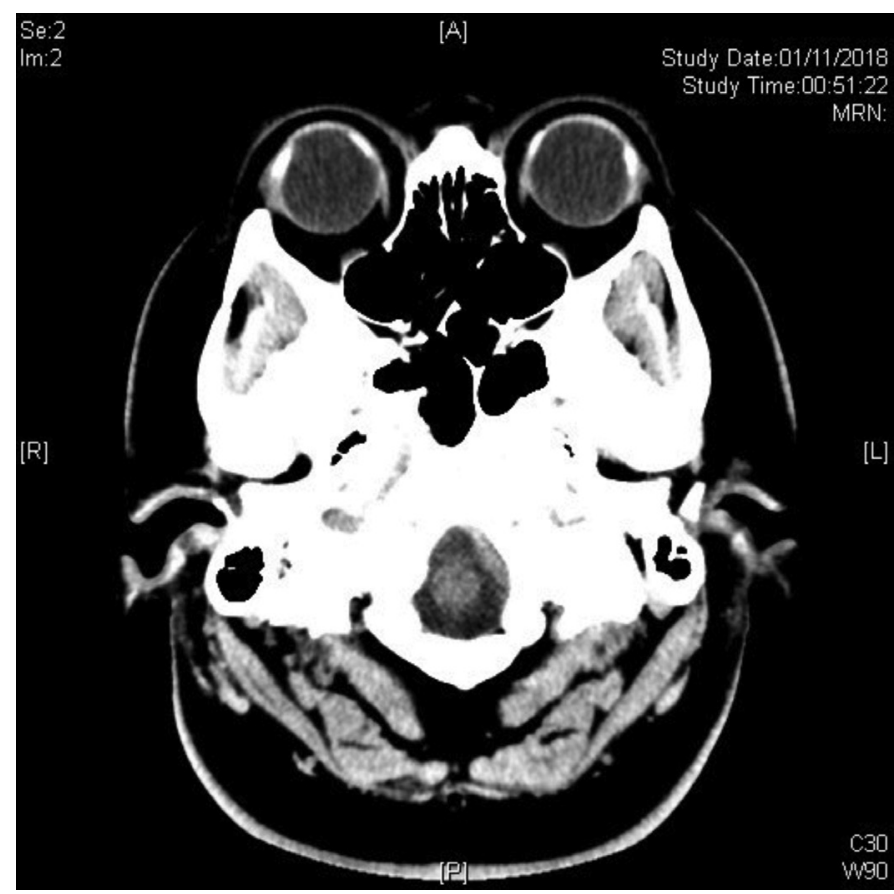

Figure 2. Transverse cut of computed tomography over orbits

Both eyes encircling band silicone buckles were seen as hyperdensity over temporal and nasal side of each globe with mild indentation into the eyeballs should be cautiously differentiated from foreign body in the orbit after a fall episode.

In conclusion, signs of RD and glaucoma on head CT are clues to poor vision in elderly fall. However, ophthalmological examination is still fundamental to establish the diagnosis.

Keywords: Computed tomography, eye, buckle, calcified trochlea

\section{Ethics}

Peer-review: Externally peer-reviewed.

\section{Authorship Contributions}

Concept: S.C.L.A., Design: S.C.L.A., Data Collection or Processing: S.C.L.A., Analysis or Interpretation: S.C.L.A., Literature Search: S.C.L.A., Writing: S.C.L.A., S.T.C.K.

Conflict of Interest: No conflict of interest was declared by the authors.

Financial Disclosure: The authors declared that this study received no financial support.

\section{References}

1. Saftari LN, Kwon OS. Ageing vision and falls: a review. J Physiol Anthropol 2018;37:11.

2. Sartin $R$, Kim C, Dissanaike $S$. Is routine head $C T$ indicated in awake stable older patients after a ground level fall? Am J Surg 2017;214:1055-1058.

3. Au SC, Ko ST. Ophthalmological signet ring sign by a glaucoma implant. Indian J Ophthalmol 2019;67:1477.

4. Sobel RK, Goldstein SM. Trochlear calcification: a common entity. Orbit 2012;31:94-96. 